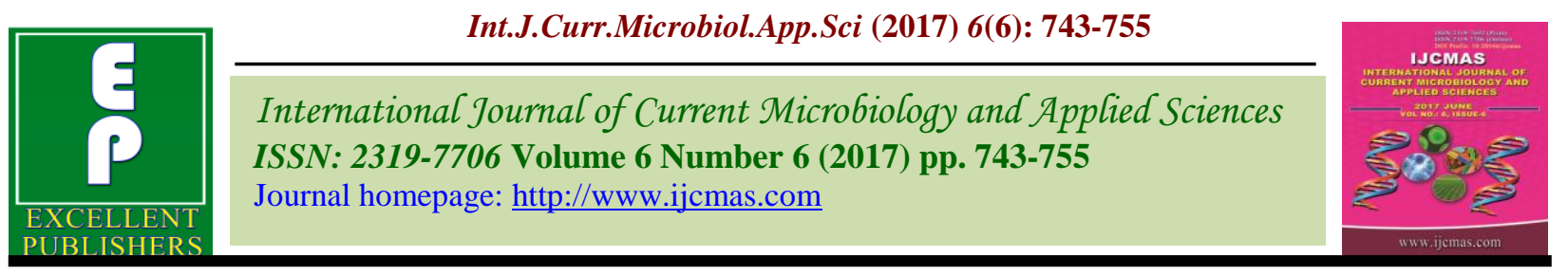

Original Research Article

https://doi.org/10.20546/ijcmas.2017.606.088

\title{
Physiological Studies on Mycelieal Growth and Exopolysaccharide Production by Fomitopsis feei
}

\author{
S.V.S.S.S.L.N. Hima Bindu* ${ }^{*}$ and M.A. Singara Charya \\ Department of Microbiology, Kakatiya University, Warangal - 506 009, Telangana State, India \\ *Corresponding author
}

A B S T R A C T

\begin{tabular}{|c|c|}
\hline $\begin{array}{l}\text { Fomitopsis feei, } \\
\text { Physiological } \\
\text { studies, Common } \\
\text { production medium, } \\
\text { Optimization, } \\
\text { Mycelial growth, } \\
\text { Exopolysaccharide. }\end{array}$ & $\begin{array}{l}\text { Mycelial growth and exopolysaccharide production of Fomitopsis feei was } \\
\text { studied in common production medium by changing different physiological } \\
\text { parameters such as carbon, nitrogen sources, inoculum size, incubation } \\
\text { time, } \mathrm{pH} \text {, temperature, agitation. Glucose, ammonium sulphate, 6mm of } \\
\text { inoculum, } 8 \text { th and } 14 \text { th days of incubation, } \mathrm{pH} 3,30^{\circ} \mathrm{C} \text { temperature and } 150 \\
\text { rpm agitation were the best for the production of mycelium. Among the } \\
\text { carbon and nitrogen sources tested glucose and malt extract were supported }\end{array}$ \\
\hline Artic & \\
\hline $\begin{array}{l}\text { Accepted: } \\
\text { 14 May } 2017 \\
\text { Available Onl } \\
10 \text { June } 2017\end{array}$ & $\begin{array}{l}\text { f inoculum, } 7 \text { and } 14 \text { days of incubation, } \mathrm{pH} 6,30^{\circ} \mathrm{C} \text { temperature, } 150 \mathrm{rpm} \\
\text { gitation supported the maximum production of exopolysaccharide among } \\
\text { le tested. }\end{array}$ \\
\hline
\end{tabular}

\section{Introduction}

In general, factors influencing the exopolysaccharide production and mycelia growth of fungi mainly include composition of culture medium and environmental conditions. The carbon source is mainly used in cellular constituent, synthesis of new cells, production of polysaccharides and as an energy source. Nitrogen comprises about $10 \%$ to $14 \%$ of cell dry weight. It is incorporated into cell mass in the form of protein and nucleic acids. Organic and inorganic nitrogen sources were investigated in order to compare exopolysaccharide (EPS) and intracellular polysaccharide (IPS) production by Tricholoma mongolicum in submerged cultivation (Wu et al., 2012). Inoculation density (or inoculum size) is also an important factor for many cell culture processes (Wu et al., 2012; Zhang and Zhong, 1997).

Appropriate harvest time selection is also an important factor to obtain the maximum fungal production in submerged culture. There will be time difference for better production of mycelia and polysaccharides. In general, the harvest time of the mycelium, in complex carbohydrate medium should not extend beyond 20 days after the inoculation in order to avoid fungal cell lysis (Wu et al., 2003). The $\mathrm{pH}$ of the medium is very important but it is often a neglected environmental factor. The medium $\mathrm{pH}$ may 
affect cell membrane function, cell morphology and structure, the uptake of various nutrients and product biosynthesis. Culture $\mathrm{pH}$ strongly influences many enzymatic processes and transport of various components across the cell membranes, which in turn support the cell growth and product production. The higher fungi usually require lower $\mathrm{pH}$ of the culture than bacteria, but not so low as moulds. It ranges usually between $\mathrm{pH} 4.0$ and 7.5.

The higher fungi usually require lower temperature for vegetation than yeast and mould (ranging $25-28^{\circ} \mathrm{C}$ ). The optimum temperature for Agaricus campestris (Moustafa, 1960) ranges $25-30^{\circ} \mathrm{C}$, for Morchella hybrida $20-25^{\circ} \mathrm{C}$ and for Phlebia radiate $28^{\circ} \mathrm{C}$ (Hatakka et al., 1986).

Agitation is also an important parameter for adequate mixing, mass and heat transfer. Agitation creates shear forces, causing morphological changes, variation in their growth and product formation, and also damage to the cell structure (Wu et al., 2012; Smith et al., 1990; Pfefferle et al., 2000).

Fomitopsis feei is a brown rot fungus belongs to the family Fomitopsidaceae. During the screening of exopolysaccharide (EPS) production by this fungus on 9 types of media, common production medium showed good result (data not shown) hence the present study is carried out to optimize the EPS production.

\section{Materials and Methods}

\section{Isolation and identification of $F$. feei}

Fomitopsis feei fruit bodies were collected from Pakhal forest, Warangal during rainy season and pure mycelial culture was developed on malt extract agar medium and was identified at molecular level by $28 \mathrm{~S}$
rDNA analysis (Hima Bindu and Singara Charya, 2017).

\section{Optimization of common production medium}

One factor at a time method was followed in which $25 \mathrm{~mL}$ of common production broth was inoculated with $6 \mathrm{~mm}$ disk of actively growing Fomitopsis feei culture plate and incubated at $28^{\circ} \mathrm{C}$ for 7 and 14 days in still condition for every factor except in agitation. Isolation and determination (Kim et al., 2002) of exopolysaccharides was done with every parameter with exopolysaccharides of 7 and 14 days old filtrates and precipitated with isopropyl alcohol in 1:4 ratios and incubated overnight at $4^{\circ} \mathrm{C}$. After incubation, the pellet obtained by centrifugation was subjected to phenol- sulphuric acid (Dubois et al., 1956) method with some modifications.

\section{Carbon source}

To find out the suitable carbon source for the exopolysaccharide production of Fomitopsis feei, 12 carbon sources of which three monosaccharides viz., arabinose, fructose, galactose, five oligosaccharides viz. lactose, maltose, raffinose, sucrose, xylose, two polysaccharides viz. cellulose, starch, and two sugar alcohols viz. mannitol and sorbitol were separately provided at $20 \mathrm{~g} / \mathrm{L}$ instead of glucose employed in common production medium and control (without carbon source) also maintained.

\section{Nitrogen source}

In the course of optimization for nitrogen source, 12 nitrogen sources viz., asparagine, diphenylamine, hexamine, gelatine, urea, sodium nitrite, potassium nitrate, malt extract, yeast extract, peptone, glycine, ammonium chloride were supplemented at $5 \mathrm{~g} / \mathrm{L}$ individually into the medium by removing ammonium sulphate used in the common 
production medium. Medium without nitrogen source (control) was also maintained for comparison.

\section{Inoculum size}

The effects of inoculum size on the cell growth and exopolysaccharide production were studied by controlling inoculation density at 3-9 $\mathrm{mm}$ size.

\section{Incubation time}

To determine the optimal period for the production of exopolysaccharide, Fomitopsis feei was cultured for 6-14 days.

\section{pH}

Fomitopsis feei was cultivated in the common production medium with different values of initial $\mathrm{pH}(3.0-8.0)$.

\section{Temperature}

To assess the optimal temperature for the production of exopolysaccharide, Fomitopsis feei was cultured at different temperate conditions $\left(20^{\circ} \mathrm{C}-45^{\circ} \mathrm{C}\right)$.

\section{Agitation}

Agitation was carried out at 50, 100, 150, 200 and 250 revolutions per minute (rpm).

\section{Results and Discussion}

\section{Effect of carbon source on} exopolysaccharide production

The mycelial growth of this fungus occurred in a variety of carbon sources, however, production of mycelia and exopolysaccharide were quite distinct. A similar observation has been reported by other investigators in macrofungal submerged cultures (Kim et al.,
2002; Chandra and Shoji, 2007). The pattern that the decline of $\mathrm{pH}$ caused by the production of organic acid resulting from high consumption of carbon source for cell growth. Among the carbon sources examined glucose $(6.88 \mathrm{~g} / \mathrm{L}, 6.04 \mathrm{~g} / \mathrm{L})$ yielded the best mycelial biomass both in 7 and 14 days respectively. The next best growth occurred in sucrose (4.92 g/L). Effect of carbon sources on dry weight of mycelial biomass and exopolysaccharide was given in figure 1 . Starch, cellulose supported less on the mycelial biomass of Fomitopsis feei may be due to the inability of this fungus to produce enzymes to metabolise these polysaccharides.

Exopolysaccharide production by various carbon sources ranged from 0.5 to $5.5 \mathrm{~g} / \mathrm{L}$. Glucose supported the best exopolysaccharide production $(5.5 \mathrm{~g} / \mathrm{L})$ after 7 days of incubation. Glucose was the most suitable carbon source for both mycelial biomass and EPS production in submerged culture of Grifolia frondosa (Bum et al., 2004; Shih et al., 2008). Arabinose, sucrose and xylose given the same production $(4.5 \mathrm{~g} / \mathrm{L})$ followed by sorbitol $(4.0 \mathrm{~g} / \mathrm{L})$. Minimum exopolysaccharide formation attained by galactose $(1.0$ and $0.5 \mathrm{~g} / \mathrm{L})$ both in 7 and 14 days. However, most of the carbon sources given good exopolysaccharide production in 7 days compared to 14 days in still condition.

Although sucrose and lactose are also good sources for the production of exopolysaccharides, glucose is a good carbon source because of its ease - of - use and low cost compared to them. However, glucose has been chosen as the best suitable carbon source for mycelium growth of a majority of mushrooms (Chang and Miles, 1989; Yang, 1986). Glucose, maltose, and mannitol were the most appropriate carbon sources for biomass and EPS production by basidiomycetes (Elisashvili et al., 2009). 


\section{Effect of glucose in different concentrations}

To study for the optimal glucose concentration, $5-30 \mathrm{~g} / \mathrm{L}$ glucose was added to the medium and tested for exopolysaccharide production and the results were shown in figure 2. It was noted that mycelial biomass increased with the increase of glucose concentration for both 7 and 14 days whereas, exopolysaccharide production varied with concentrations of glucose. The highest mycelial growth was observed with $30 \mathrm{~g}$ glucose in both 7 and 14 days $(9.36 \mathrm{~g} / \mathrm{L}, 9.96$ $\mathrm{g} / \mathrm{L}$ respectively). $15 \mathrm{~g}$ glucose $(4.0 \mathrm{~g} / \mathrm{L}$ in 14 days) and $25 \mathrm{~g}$ glucose $(4.0 \mathrm{~g} / \mathrm{L}$ in 7 days) supported moderate exopolysaccharide production. Whereas, further increasing glucose concentration from $25 \mathrm{~g}-30 \mathrm{~g}$ exerted negative effect on production, for high EPS production, $C$. indica required above $15 \mathrm{~g} / \mathrm{l}$ glucose (Anandapandian and Eyini, 2014). Different mushrooms prefer different concentration of carbon source for best exopolysaccharide production (Chandra and Shoji, 2007; Elisasvilli et al., 2009).

\section{Effect of nitrogen source on exopolysaccharide production}

Figure 3 showed the effect of nitrogen sources on mycelial biomass and exopolysaccharide production after the incubation of 7 and 14 days. The highest mycelial biomass recorded from ammonium sulphate in 7 days $(6.88 \mathrm{~g} / \mathrm{L})$ followed by peptone $(6.52 \mathrm{~g} / \mathrm{L}, 6.30 \mathrm{~g} / \mathrm{L}$ for 14 and 7 days respectively). Diphenyl amine did not support the growth of this fungus; this may be because of its acidic $\mathrm{pH}$. In general, good mycelial growth does not seem to be a determining factor for a high production of exopolysaccharides. Maximum exopolysaccharide production was noted in malt extract and peptone in 14 days $(8.5 \mathrm{~g} / \mathrm{L}, 7.5$ $\mathrm{g} / \mathrm{L}$ respectively). Similar results were reported (Shih et al., 2008; Chang et al., 2006). Peptone is the best nitrogen source for cordycepin biosynthesis from Cordyceps militaris (Xian and Zhong, 2006). But in our study, peptone is the second most important nitrogen source. In comparison with organic nitrogen sources, inorganic sources gave rise to relatively lower mycelial biomass. This is due to most of the basidiomycete fungi prefer complex organic nitrogen sources for their favorable submerged cultures because certain essential amino acids could scarcely be synthesized from inorganic nitrogen sources (Shih et al., 2008). It is also seen that organic nitrogen sources were more effective than inorganic nitrogen sources for facilitating mycelial growth and EPS production (Yun et al., 2016). Malt extract was further examined in different concentrations since it showed the highest result in both still and shake conditions although biomass production was moderate with this source. Earlier report also proved that complex organic nitrogen sources led to better growth of mushroom species (Chang and Miles, 1989).

\section{Effect of malt extract in different concentrations}

1-7 g/L concentrations of malt extract was applied to identify suitable concentration for mycelial growth and exopolysaccharide production (Fig. 4). Maximum mycelial biomass $(11.84 \mathrm{~g} / \mathrm{L})$ was observed with $7 \mathrm{~g}$ of malt extract followed by $3 \mathrm{~g}$ of malt extract $(11.24 \mathrm{~g} / \mathrm{L})$ in 14 days. The highest exopolysaccharide production came from $4 \mathrm{~g}$ of malt extract $(8.5 \mathrm{~g} / \mathrm{L})$ followed by $2 \mathrm{~g}$ of malt extract $(7.5 \mathrm{~g} / \mathrm{L})$.

\section{Effect of inoculum size on exopolysaccharide production}

Mycelial growth was highest $(6.88 \mathrm{~g} / \mathrm{L})$ with $6 \mathrm{~mm}$ of inoculum size. After that it was decreased even though inoculum size was increased. The maximum exopolysaccharide production was observed with inoculum of 6 $\mathrm{mm} \quad(5.5 \mathrm{~g} / \mathrm{L}, \quad 4.0 \mathrm{~g} / \mathrm{L}$ for 7,14 days respectively). 
Fig.1 Effect of carbon source on mycelial dry weight and exopolysaccharide production
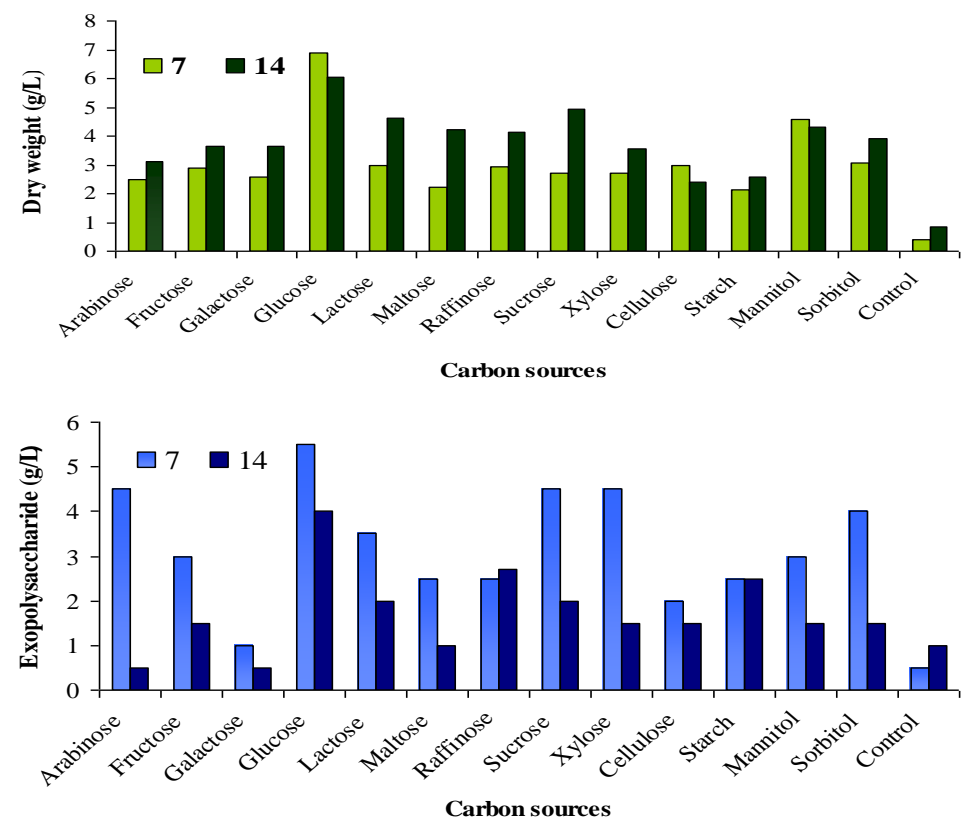

Fig.2 Effect of glucose concentration on mycelial dry weight and exopolysaccharide production
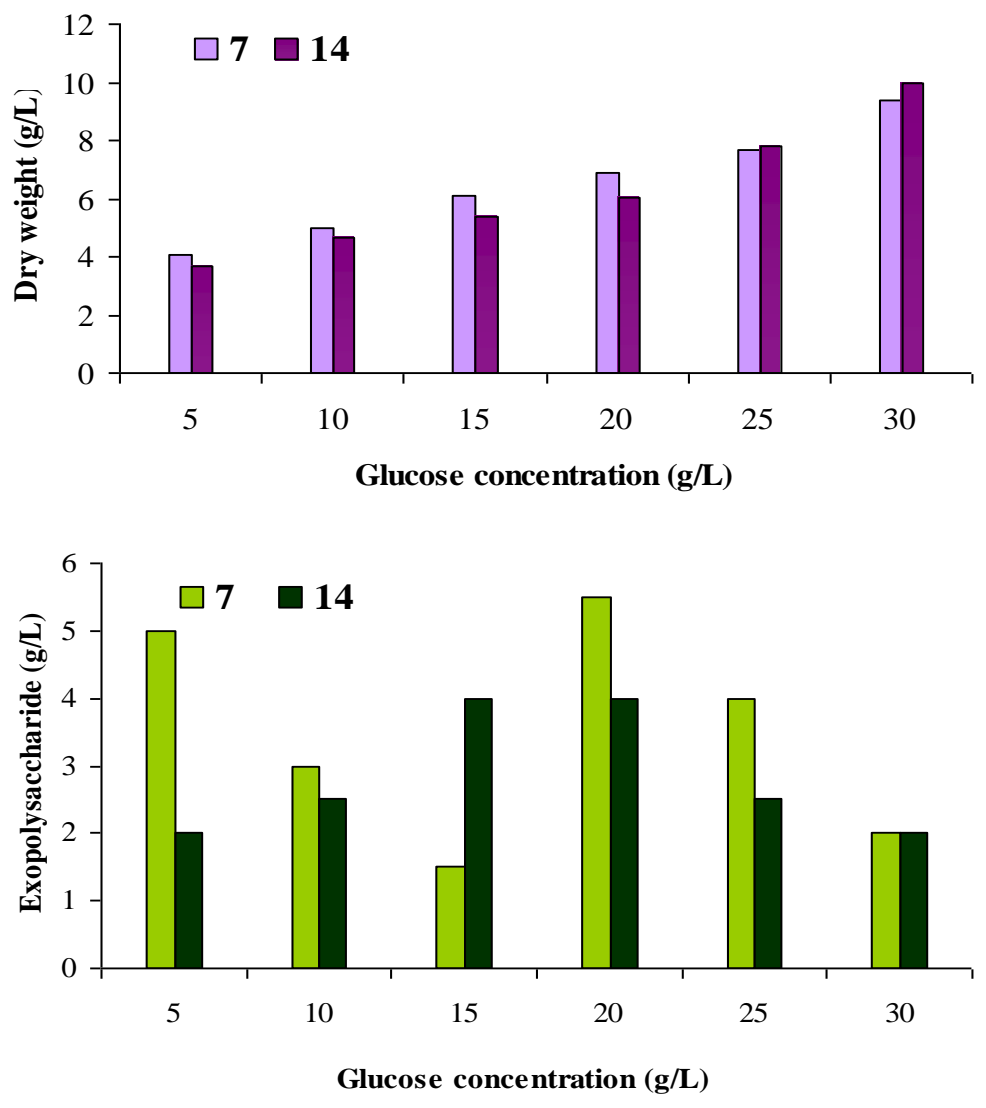
Fig.3 Effect of nitrogen source on mycelial dry weight and exopolysaccharide production
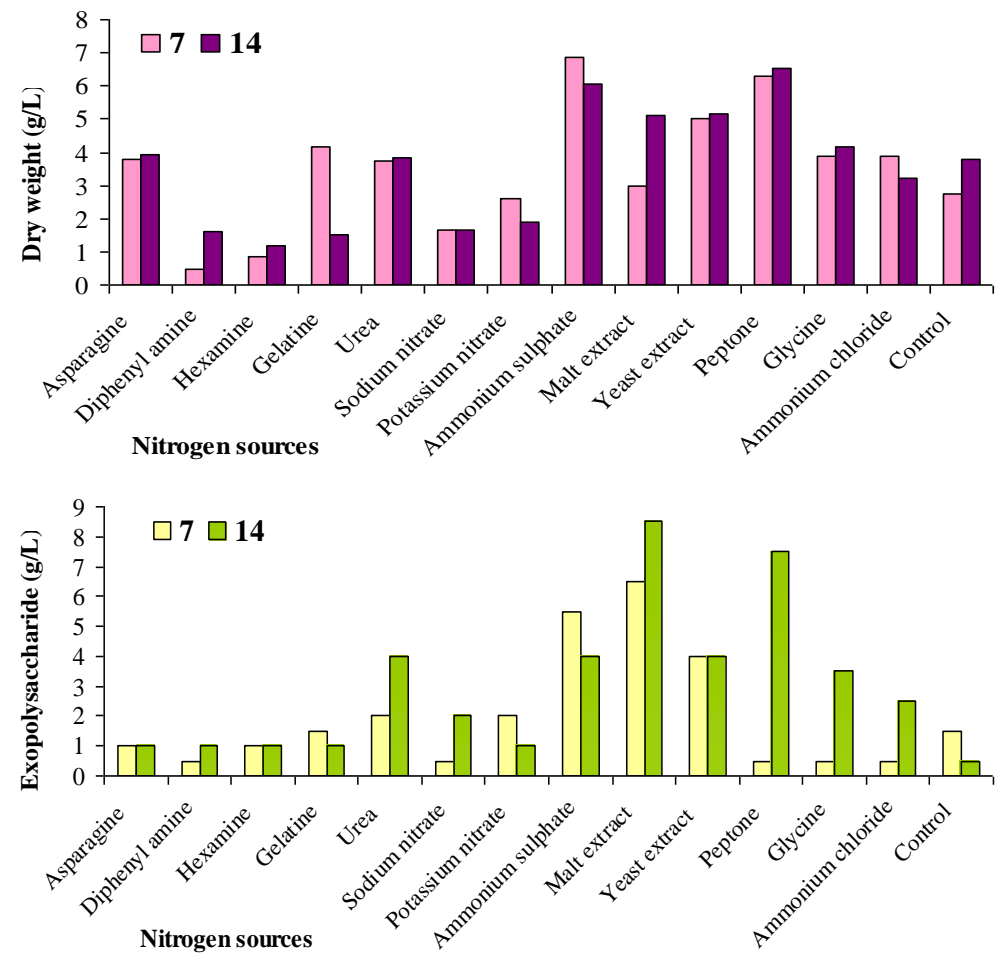

Fig.4 Effect of malt extract concentration on mycelial dry weight and exopolysaccharide production
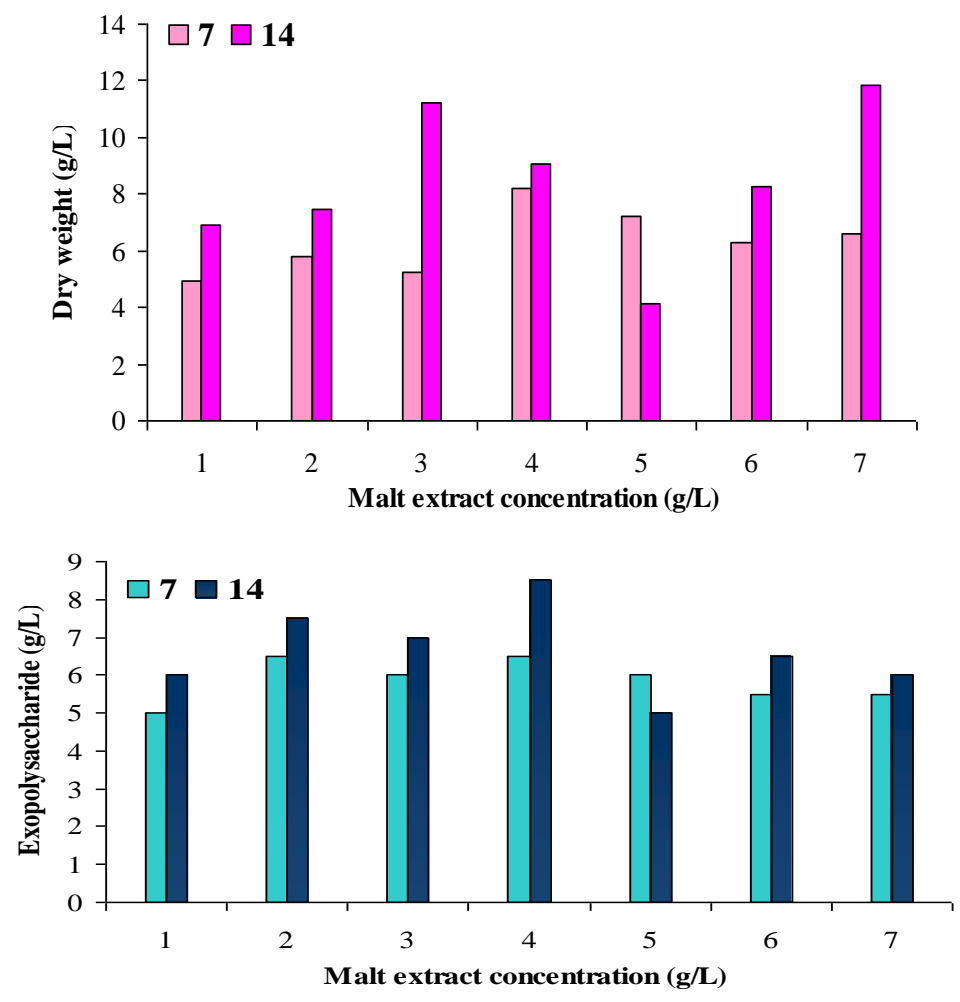
Fig.5 Effect of inoculum size on mycelial dry weight and exopolysaccharide production
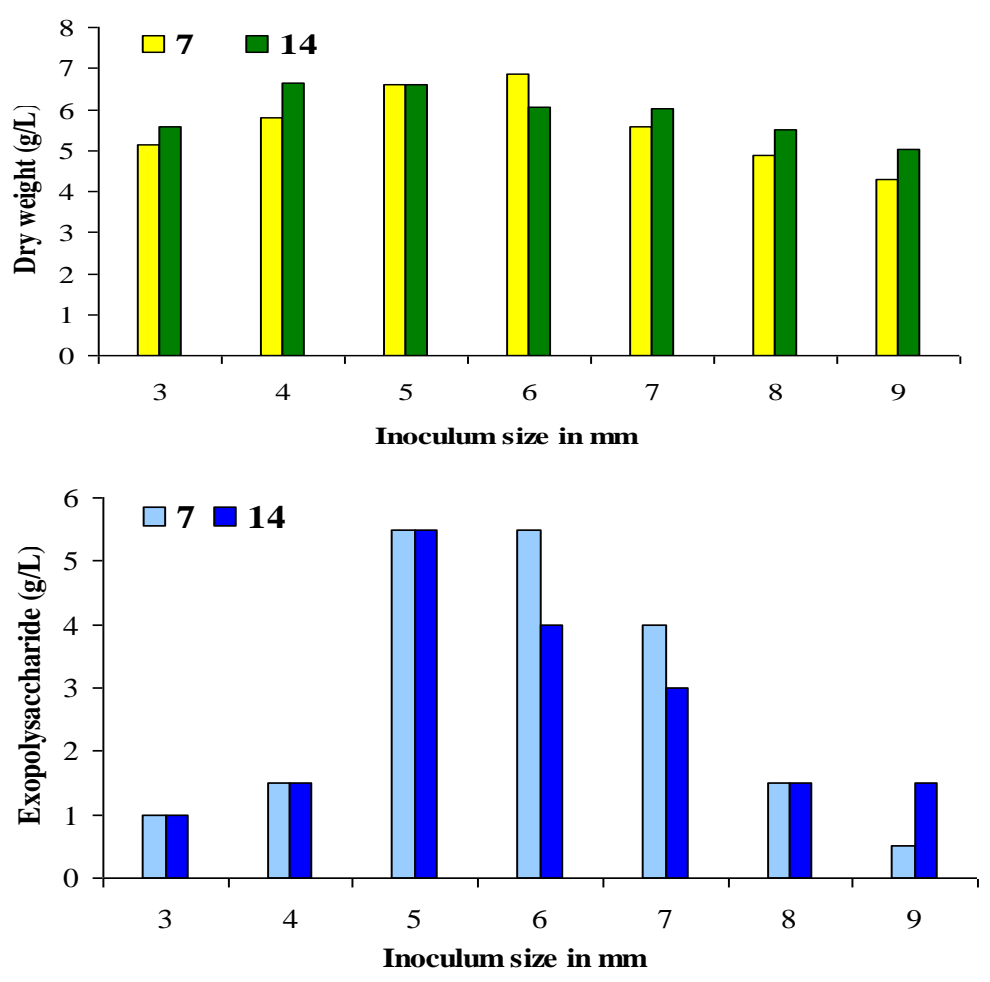

Fig.6 Effect of incubation time on mycelial dry weight and exopolysaccharide production
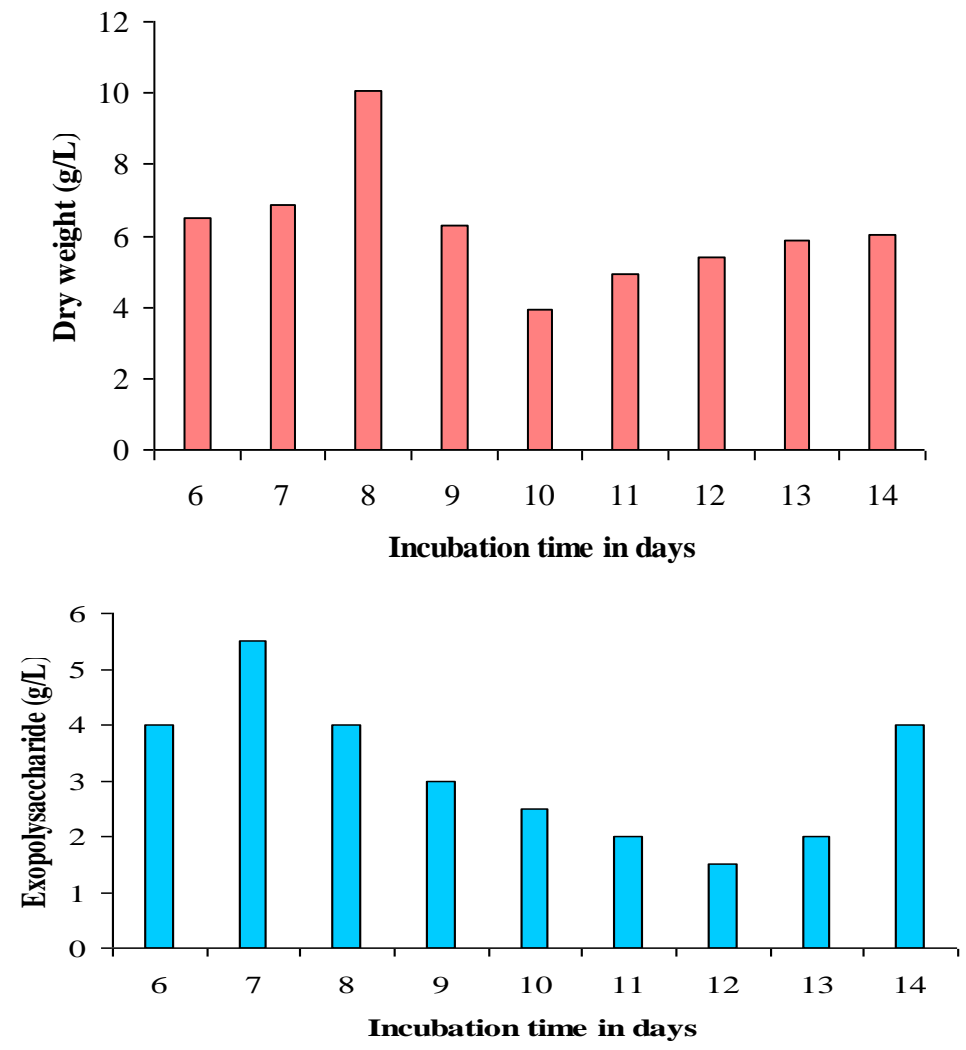
Fig.7 Effect of initial pH on mycelial dry weight and exopolysaccharide production
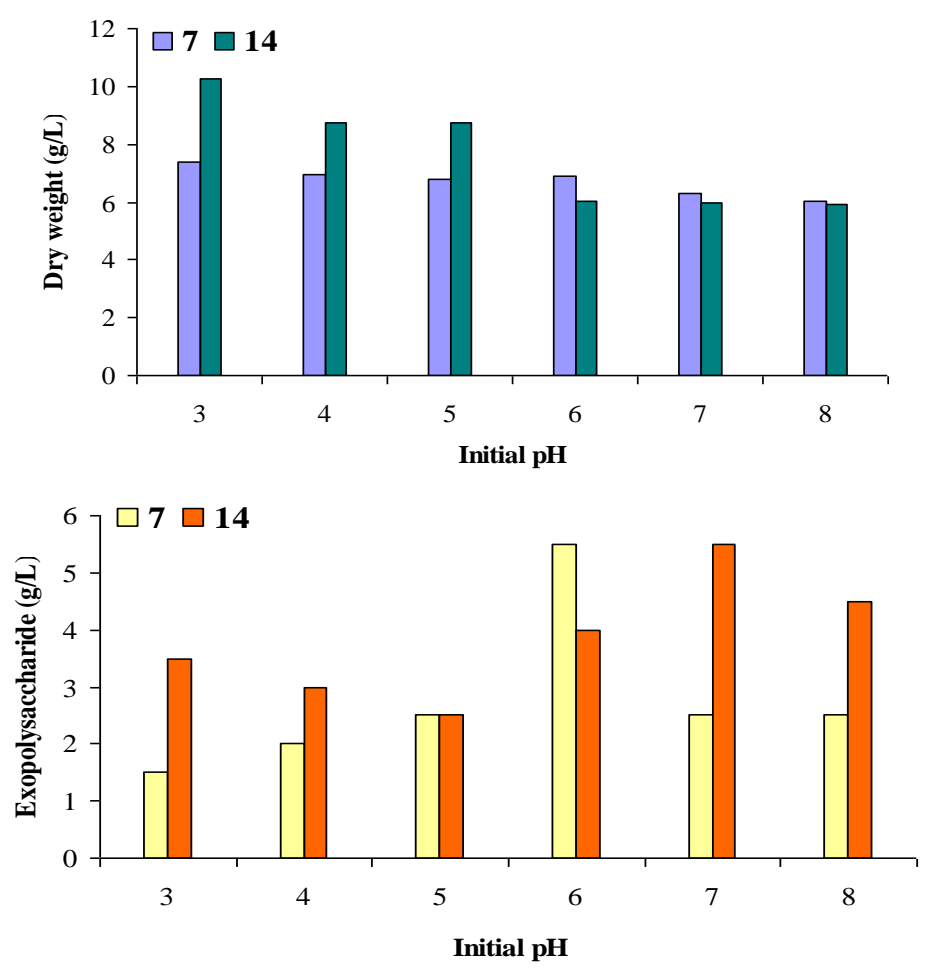

Fig.8 Effect of temperature on mycelial dry weight and exopolysaccharide production
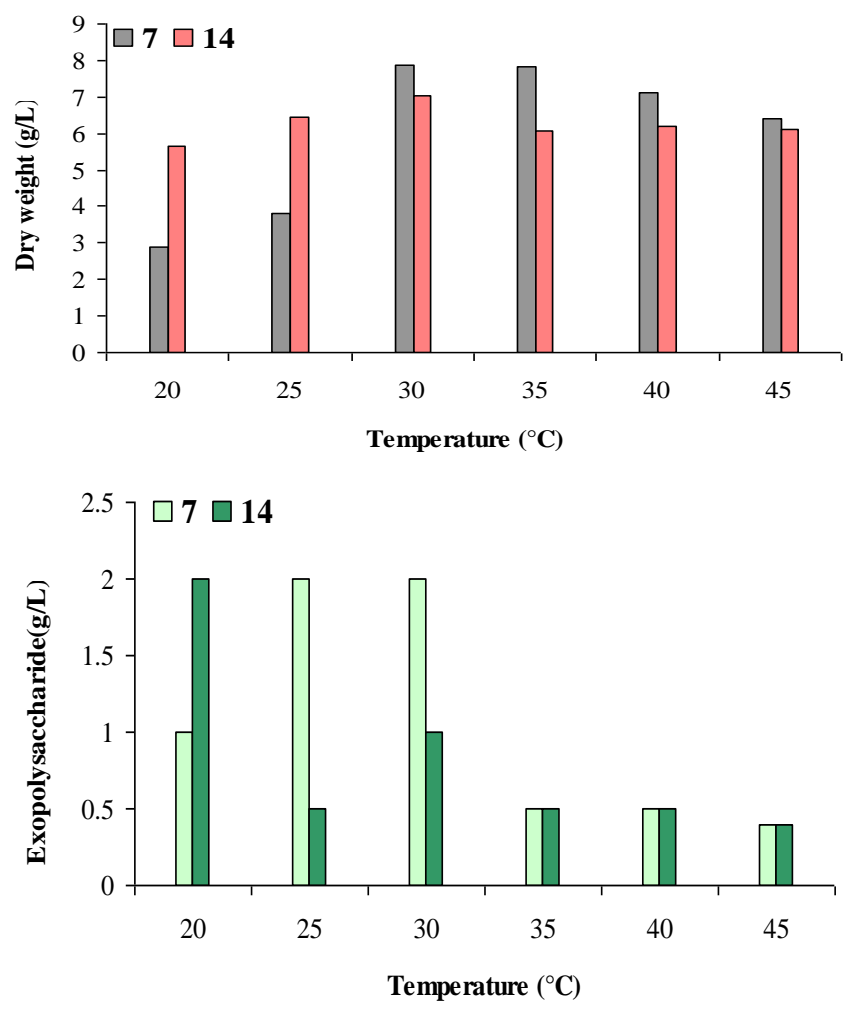
Fig.9 Effect of agitation on mycelial dry weight and exopolysaccharide production
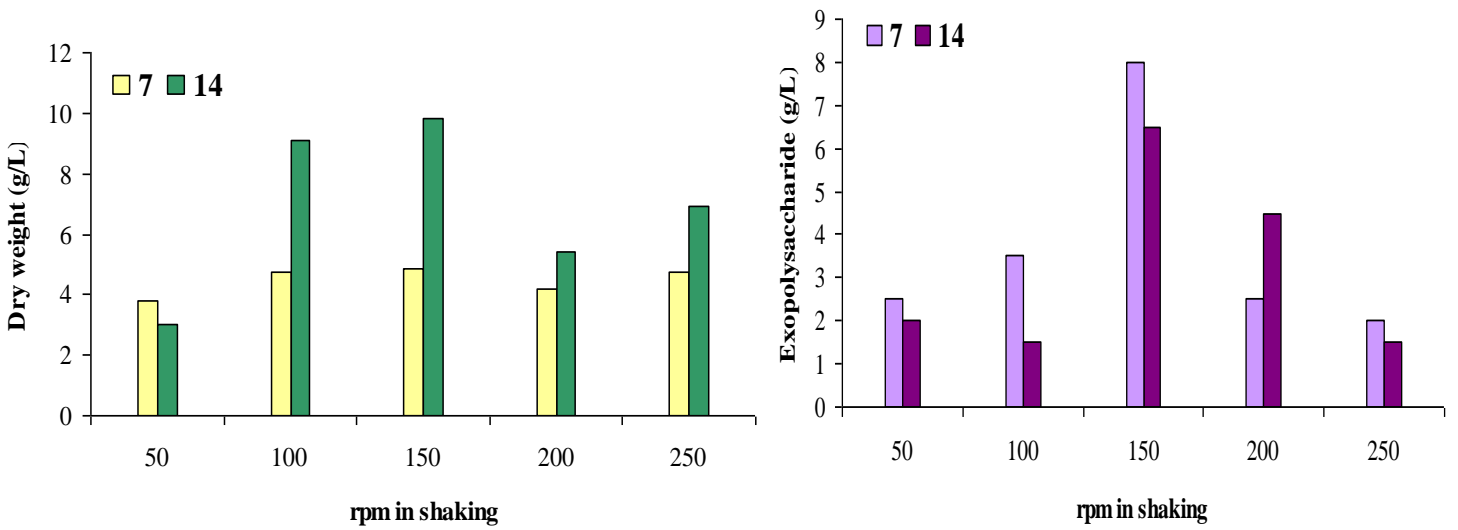

Fig.10 Growth of Fomitopsis feei in shaking condition

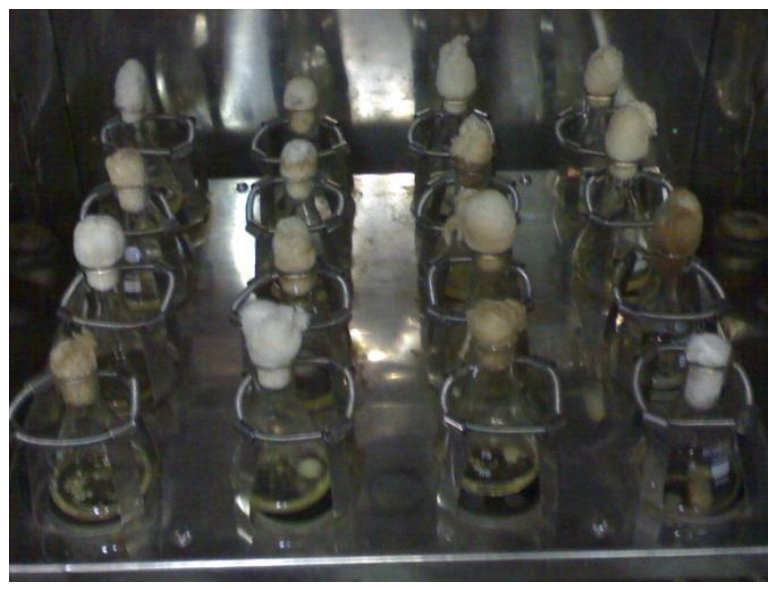

Mycelial biomass and polysaccharide production were highest (Jian et al., 2006) at an inoculum size of $6 \%$. The same decrease in exopolysaccharide production was observed with increasing inoculum size after this.

The amount of inocula could affect the length of the fermentation period. Small inoculum size may extend fermentation period, which made it susceptible to bacterial contamination; large inoculums size may quicken medium nutrients consumption, also produce large amounts of waste products. At lower inoculum levels the yield was very low (Tang et al., 2008). The decrease seen with large inoculum size could be due to the shortage of the nutrients available for the large biomass and faster growth of the culture. Figure 5 showed the effect of inoculum size on biomass dryweight and exopolysaccharide production from $F$. feei.

Effect of incubation time on exopolysaccharide production

The highest mycelial growth was obtained from 8 days old culture $(10.04 \mathrm{~g} / \mathrm{L})$ thereafter, these values were decreased and again increased at day $14 \quad(6.04 \quad \mathrm{~g} / \mathrm{L})$. Exopolysaccharide production reached a maximal value of $5.5 \mathrm{~g} / \mathrm{L}$ on day 7 but decreased then onwards and again observed high on day 14 (4 g/L). Hence, a 7 and 14 day period was suitable for stimulation of mycelia 
and exopolysaccharide in submerged culture of Fomitopsis feei and all of the following fermentations were carried out for both 7 and 14 days when optimizing the conditions in the submerged culture. Figure 6 showed that the activity of polysaccharide production was rather short-phased, even though mycelia growth continues for a longer duration. From 6th to 7th day, there was a progressive increase in EPS production, however, from 8th to 13th there was a highly significant decrease in EPS production and again increased on 14th day. Different species showed different incubation time for the production of EPS according to the previous research. Polysaccharide production by Acremonium diospyri was parallel with biomass over the first 10 days then ceased (Seviour and Hensgen, 1983). Mycelial biomass and exopolysaccharide concentrations were the highest at day 14 (Lin and Sung, 2006).

\section{Effect of pH on exopolysaccharide production}

The mycelial growth and exopolysaccharide production were significantly affected by culture $\mathrm{pH}$ of $F$. feei (Fig. 7). In general, the optimal medium $\mathrm{pH}$ for cell growth is around the lower range from 2-4 and the optimal medium for exopolysaccharide formation is around the high range from 5-7. The highest EPS production was at an initial $\mathrm{pH}$ of 5.5 in submerged fermentation of Ganoderma lucidum (Fang and Zhong, 2002). The final $\mathrm{pH}$ was mainly dropped to acidic in the media at the end of the incubation time.

The result of our investigation was also observed the same findings. The highest concentration of mycelial growth was obtained at $\mathrm{pH}$ values of 3 and $4(10.24 \mathrm{~g} / \mathrm{L}$, $8.76 \mathrm{~g} / \mathrm{L}$ respectively) in 14 days. This concentration dropped sharply out of this range. The maximum exopolysaccharide production was obtained at $\mathrm{pH} 6$ and 7 (5.5 $\mathrm{g} / \mathrm{L})$ followed by $\mathrm{pH} 8(4.5 \mathrm{~g} / \mathrm{L})$. It has been reported that a wide variety of mushrooms have also acidic $\mathrm{pH}$ optima for mycelial growth and exopolysaccharide production (Kim et al., 2002). The results are similar to those reported for other exopolysaccharide synthesizing fungi such as $A$. pullulans (Lacroix et al., 1985), Sclerotium glucanicum (Wang and Nail, 1995) for which the $\mathrm{pH}$ optimum for growth has been shown to be lower than that for EPS production.

Effect of temperature on exopolysaccharide production

The highest mycelial biomass obtained at $30^{\circ} \mathrm{C}(7.88 \mathrm{~g} / \mathrm{L})$ after 14 days of incubation. The maximum exopolysaccharide production was attained at $30^{\circ} \mathrm{C}(2.0 \mathrm{~g} / \mathrm{L})$ after 14 days of incubation. Exopolysaccharide production was supported (Maziero et al., 1999) by the temperatures between 25 and $30^{\circ} \mathrm{C}$.

Figure 8 showed the effect of temperature on mycelial biomass and exopolysaccharide production. The optimum temperature was found to be $30^{\circ} \mathrm{C}$. This temperature optimum is quite similar to the results reported (Kang et al., 1997) from other liquid cultures of different species of $P$. linteus. It is comparable that many kinds of mushrooms have relatively low temperature optima ranging from $20-25^{\circ} \mathrm{C}$ in their submerged cultures (Bae et al., 2000; Park et al., 2001). Therefore, $28-30^{\circ} \mathrm{C}$ was chosen to be the incubation temperature for further experiments.

\section{Effect of agitation on exopolysaccharide production}

The effect of agitation on mycelial biomass and exopolysaccharide production was showed in figure 9. The highest mycelial growth was obtained at $150 \mathrm{rpm}(9.84 \mathrm{~g} / \mathrm{L})$ 
followed by $100 \mathrm{rpm}(9.12 \mathrm{~g} / \mathrm{L})$ after 14 days of incubation. Exopolysaccharide production was also high at $150 \mathrm{rpm}(8 \mathrm{~g} / \mathrm{L}$ and $6.5 \mathrm{~g} / \mathrm{L}$ for both 7 and 14 days respectively). Growth of mycelium in shaking condition was in pellet shape, might be because of agitation (Fig. 10). The agitation speed has greatly affected the production rate and maximum concentration of polysaccharides, for which the optimal rotation speed has been reported at $150 \mathrm{rpm}$ for flask cultures (Yang and Liau, 1998; Chun et al., 2006). The polysaccharide production declined sharply, indicating higher rotation speed may inhibit the release of polysaccharide. The same phenomenon was observed in EPS production of Fomes fomentarius (Chen et al., 2008).

The results revealed that same source did not support the best production of mycelium and exopolysaccharide. The result is considered helpful for further investigation on the diversity of polysaccharide formation from this medicinal fungus in bulk quantities for various purposes.

\section{References}

Anandapandian, K.T.K., and Eyini, M. 2014. Optimization of mycelial growth and exopolysaccharide production By Calocybe Indica using response surface methodology. J. Adv. Med. Life Sci., 1: 1-7.

Bae, J.T., Sinha, J.A., Park, J.P., Song, C.H., and Yun, J.W. 2000. Optimization of submerged culture conditions for exobiopolymer production by Paecilomyces japonica. J. Mic. Biotech., 10: 482-7.

Bum, C.L., Bae, J.T., Pyo, H.B., Choe, T.B., Kim, S.W., Hwang, H.J., and Yun, J.W. 2004. Submerged culture conditions for the production of mycelial biomass and exopolysaccharides by the edible basidiomycete Grifola frondosa. Enz. Microb. Technol., 35: 369-376.
Chandra, P.P., and Shoji. 2007. Submerged culture conditions for mycelial yield and polysaccharides production by Lyophyllum decastes. Food Chem., 105: 641-646.

Chang, M.Y., Tsai, G.J., and Houng, J.Y. 2006. Optimization of the medium composition for the submerged culture of Ganoderma lucidum by Taguchi array design and steepest ascent method. Enz. Microb. Technol., 38: 407-414.

Chang, S.T., and Miles, P.G. 1989. Edible mushrooms and their cultivation. CRC press, Boca Raton, FL.

Chen, W., Zhao, Z., Chen, S.F., and Li, Y.Q. 2008. Optimization for the production of exopolysaccharide from Fomes fomentarius in submerged culture and its antitumor effect in vitro. Biores. Tech., 99: 3187-94.

Chun, P.X., Kim, S.W., Hwang, H.J., and Yun, J.W. 2006. Production of exopolysaccharides by submerged culture of an enthomopathogenic fungus, Paecilomyces tenuipes C240 in stirred - tank and airlift reactors. Bioresour. Technol., 97: 770-777.

Dubois, M., Gilles, K.A., Hamilton, J.K., Rebers, P., and Smith, F. 1956. Colorimetric method for determination of sugars and related substances. Anal. Chem., 28: 350-356.

Elisashvili, V.I., Kachlishvili, E.T., Wasser, S.P. 2009. Carbon and nitrogen source effects on basidiomycetes exopolysaccharide production. Appl. Biochem. Mic., 45: 531-535.

Fang, Q.H., and Zhong, J.J. 2002. Effect of initial $\mathrm{pH}$ on production of ganoderic acid and polysaccharide by submerged fermentation of Ganoderma lucidum. Proc. Biochem., 37: 769-74.

Hatakka, A.I., Tervilä-Wilo, A.L., and NikuPaavola, M.L. 1986. Production and properties of ligninases of the white-rot 
fungus Phelbia radiata. In Biotechnology in the Pulp and Paper Industry, Stockholm (Sweden). STFI.

Hima Bindu, S.V.S.S.S.L.N and Singara Charya MA. 2017. Growth pattern, molecular identification and bio molecules analysis of Fomitopsis feei. Invention J. Res. Technol. Eng. \& Manage., 1(9):16-26.

Jian, H.X., Chen, D.X., Wan, W.H., Hu, X.J., Qi, Y., Liang, Z.Q. 2006. Enhanced simultaneous production of mycelia and intracellular polysaccharide in submerged cultivation of Cordyceps jiangxiensis using desirability functions. Proc. Biochem., 41: 1887-1893.

Kang, T.S., Lee, D.G., and Lee, S.Y. 1997. Isolation and Mycelial Cultivation Submerged of Phellinus sp. The Korean J. Myc., 25: 257-67.

Kim, S.W., Hwang, H.J., Xu, C.P., Na, Y.S., Song, S.K., and Yun, J.W. 2002. Influence of nutritional conditions on the mycelial growth and exopolysaccharide production in Paecilomyces sinclairii. Lett. Appl. Mic., 34: 389-393.

Lacroix, C., LeDuy, A., Noel, G., and Choplin, L. 1985. Effect of $\mathrm{pH}$ on the batch fermentation of pullulan from sucrose medium. Biotech. Bioeng., 27: 202-207.

Lin, E.S., and Sung, S.C. 2006. Cultivating conditions influence exopolysaccharide production by the edible Basidiomycete Antrodia cinnamomea in submerged culture. Int. J. Food Micr., 108: 182187.

Maziero, R., Cavazzoni, V., and Bononi, V.L. 1999. Screening of basidiomycetes for the production of exopolysaccharide and biomass in submerged culture. Rev. de Mic., 30: 77-84.

Moustafa, A.M. 1960. Nutrition and the development of mushroom flavor in
Agaricus campestris mycelium. Appl. Micro., 8(1): 63-67.

Park, J.P., Kim, S.W., Hwang, H.J., and Yun, J.W. 2001. Optimization of submerged culture conditions for the mycelial growth and exobiopolymer production by Cordyceps militaris. Lett. App. Mic. 33: 76-81.

Pfefferle, C., Theobald, U., Gürtler, H., and Fiedler, H.P. 2000. Improved secondary metabolite production in the genus Streptosporangium by optimization of the fermentation conditions. J. Biotech., 80: $135-42$.

Seviour, R.J., and Hensgen, K. 1983. Exocellular glucan production by Acremonium diospyri. FEMS Micro. Lett., 16: 343-347.

Shih, L., Chou, B.W., Chen, C.C., Wu, J.Y., and Hsieh, C. 2008. Study of mycelial growth and bioactive polysaccharide production in batch and fed-batch culture of Grifola frondosa. Biores. Tech., 99: 785-93.

Smith, J.J., Lilly, M.D., and Fox, R.I. 1990. The effect of agitation on the morphology and penicillin production of Penicillium chrysogenum. Biotech. Bioeng., 35: 1011-23.

Tang, Y.J., Zhu, L.L., Li, D.S., Mi, Z.Y., and Li, H.M. 2008. Significance of inoculation density and carbon source on the mycelial growth and Tuber polysaccharides production by submerged fermentation of Chinese truffle Tuber sinense. Proc. Biochem., 43: 576-586.

Wang, Y., and McNeil, B. 1995. PH effects on exopolysaccharide and oxalic acid production in cultures of Sclerotium glucanicum. Enz. Mic. Tech., 17: 12430.

Wu, J.Z., Cheung, P.C., Wong, K.H., and Huang, N.L. 2003. Studies on submerged fermentation of Pleurotus tuber-regium (Fr.) Singer-Part 1: 
physical and chemical factors affecting the rate of mycelial growth and bioconversion efficiency. Food Chem., 81: 389-93.

Wu, X., Xu, R., Ren, Q., Bai, J., and Zhao, J. 2012. Factors affecting extracellular and intracellular polysaccharide production in submerged cultivation of Tricholoma mongolicum. African J. Microbiol. Res., 6: 909-16.

Xian, B.M., and Zhong, J.J. 2006. Significant effect of NH4+ on cordycepin production by submerged cultivation of medicinal mushroom Cordyceps militaris. Enz. Microb. Technol., 38: 343-350.

Yang, F.C., and Liau, C.B. 1998. The influence of environmental conditions on polysaccharide formation by
Ganoderma lucidum in submerged cultures. Proc. Biochem., 33: 547-53.

Yang, X.M. 1986. Cultivation of edible mushroom in China. Agriculture Printing House, Beijing, PR China. 489510.

Yun, Li., Shoujun, Guo, and Hui, Zhu. 2016. Statistical optimization of culture medium for production of exopolysaccharide from endophytic fungus Bionectria ochroleuca and its antitumor effect in vitro. EXCLI J., 15: 211-220.

Zhang, Y.H., and Zhong, J.J. 1997. Hyper production of ginseng saponin and polysaccharide by high density cultivation of Panax notoginseng cells. Enz. Mic. Tech., 21: 59-63.

\section{How to cite this article:}

Hima Bindu, S.V.S.S.S.L.N. and Singara Charya, M.A. 2017. Physiological Studies on Mycelieal Growth and Exopolysaccharide Production by Fomitopsis feei. Int.J.Curr.Microbiol.App.Sci. 6(6): 743-755. doi: https://doi.org/10.20546/ijcmas.2017.606.088 